\title{
Combination of Spinal Anesthesia and Usg- Guided Low-Dose Bilateral Infraclavicular Block in a Patient with Difficult Airway: A Rare Case Report
}

ISSN: 2639-0531

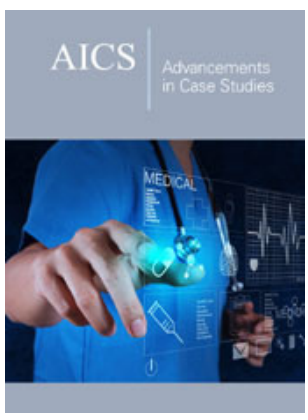

*Corresponding author: Hakan Akelma, Department of Anesthesiology and Reanimation, Turkey

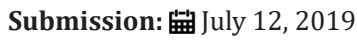

Published: 㘹July 18, 2019

Volume 2 - Issue 1

How to cite this article: Hakan A, Fikret S, Mustafa B, İbrahim A, Esra A B, etal. Combination of Spinal Anesthesia and UsgGuided Low-Dose Bilateral Infraclavicular Block in a Patient with Difficult Airway: A Rare Case Report. Adv Case Stud.2(1). AICS.000526.2019.

DOI: 10.31031/AICS.2019.02.000526

Copyright@ Hakan Akelma, This article is distributed under the terms of the Creative Commons Attribution 4.0 International License, which permits unrestricted use and redistribution provided that the original author and source are credited.

\author{
Hakan Akelma*, Fikret Salık, Mustafa Bıçak, İbrahim Andan, Esra Aktiz Bıçak \\ and Akif Yildırım
}

Gazi Yaşargil Training and Research Hospital, Turkey

\begin{abstract}
Brachial plexus blockade is commonly used in upper extremity surgery because it causes a good effective intraoperative cooperation anesthesia and analgesia. When performed under USG guidance, it has high success and low complication rate. Since multiple extremity burns are present and difficult airway patients have increased blood supply in the extremities and provide long-term analgesia in burn wound healing, regional anesthesia is a good choice. In anesthesia approach, regional anesthesia technique is a good alternative to general anesthesia especially in patients with large burns accompanied by facial and neck burns. In this case, we aimed to present a case of spinal anesthesia in addition to successful lowdose bilateral infraclavicular block with USG in a patient with multiple limb burns and a difficult airway suspicion.
\end{abstract}

Keywords: Burn; Difficult airway; Bilateral infraclavicular block; Spinal anesthesia

Introduction

Brachial plexus blockage is frequently used in upper extremity surgery such as arm, forearm and hand surgery because it provides good intraoperative cooperation, safe anesthesia and postopertifically effective analgesia. In recent years, the use of ultrasound (USG) in anesthesia practice has led to the separation of vascular structures from neural structures. USG guidance has been shown to be superior in terms of reducing total anesthetic volume requirement and complication rate when compared with blind technique [1,2]. With these advantages, USG has become indispensable in both peripheral and upper extremity blocks. Infraclavicular block has high success rate and low complication rate under USG guidance. Although the risk of pneumothorax is high in infraclavicular block, the use of USG significantly reduces this risk. In addition, one of the most important factors that emphasize this block is that diaphragm nerve paralysis and horner syndrome develop less than supraclavicular block.

Postoperative pain causes delayed ambulation in burn patients under general anesthesia and this leads to prolonged hospital stay. Regional anesthesia is a widely used method because it provides both good intraoperative anesthesia and postoperative analgesia. In addition, because it increases blood supply to the extremities, it is beneficial for burn wound healing. Despite technological advances, it remains one of the most feared scenarios of difficult airway anesthesia practice. In multiple emergency patients with facial and neck burns, limited mask ventilation and prediction of possible difficult intubation necessitates regional anesthesia rather than general anesthesia. The presence of regional anesthesia techniques in this type of emergency surgical approach is still the gold standard. In this study, we aimed to present a case of spinal anesthesia in addition to low dose bilateral infraclavicular block that we administered USG-guided to the patient who developed face, bilateral both arms, forearm, wrist, hand and finger and both thigh burns due to gas stove burst burn.

\section{Case}

When automobile exhaust mechanic 50-year-old male patient poured the old auto oil from his own workplace to the stove in order to warm, the flame exploded and took a fire. The 
patient's clothes were on fire. The patient was treated with water. However, the flame increased. The patient was extinguished with a fire extinguisher and hospitalized in another center. The patient was transferred to our burn unit 3 days later because it was thought that the burn treatment would be inadequate. When the patient was admitted to our clinic, the general condition was moderate, conscious, and cooperative-oriented. The patient's vital signs were normal, and he had second- and third-degree burns on the face, both upper extremity arms, forearms, hands and fingers and $30 \%$ of both lower extremities (Figure 1,2).

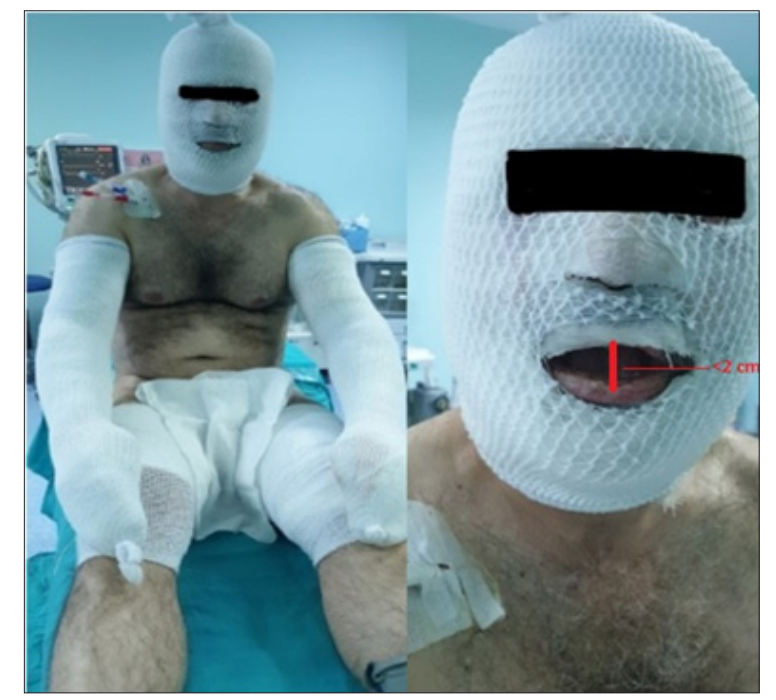

Figure 1: Patient with facial and extremity burns.

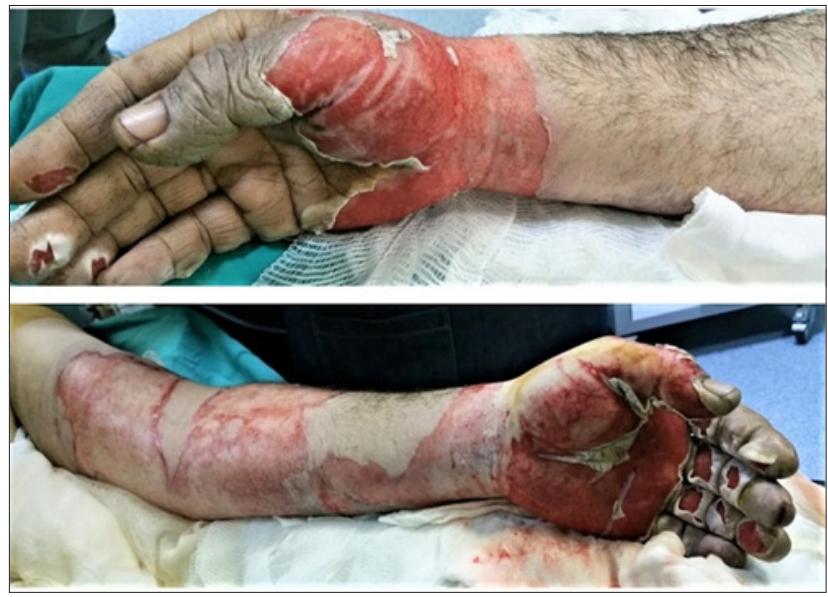

Figure 2: Bilateral 2nd and 3rd degree burns on both hands.

The patient was washed with antiseptic shampoo and burn wounds were covered sterile. The patient was evaluated preoperatively and there was no additional disease history. Physical examination revealed that the patient's mouth opening was insufficient due to orolabial burn (mouth opening $<3 \mathrm{~cm}$ ). Difficult ventilation and difficult intubation were prescribed in the patient with a face wrapped. For difficult intubation and ventilation, a Video Laryngoscope and 4 and 5 two-size laryngoscopes were used and two sizes of ProSeal laryngeal masks (LMA) were prepared (No: 4,5 ). In addition, because of the deep and wide burn wounds, it was decided to perform USG-guided bilateral low-dose infraclavicular block and spinal anesthesia instead of general anesthesia to increase postoperative analgesia and extremity blood supply. After the patient was given detailed information about the procedure, written consent was obtained and general anesthesia conditions were provided, the patient was taken to the operating table; blood pressure arterial was measured as $115 / 70 \mathrm{~mm} \mathrm{Hg}$, pulse: $80 / \mathrm{min}$., and toe saturation was $99 \%$ without $\mathrm{O}_{2} .2 \mathrm{~L} / \mathrm{min}$.

Oxygen was given with nasal cannula. $2 \mathrm{mg}$ midazolam was administered intravenously. Firstly, the patient was planned to undergo spinal anesthesia, and then the sterile drape was covered and the L4-5 level was entered into the subarachnoid space with a 26 gauge Quincke spinal needle (M. Schilling GmBH, Deutschland). Following free cerebrospinal fluid (CSF) flow, Heavy-bupivacaine 15mg (Marcaine Spinal Heavy 0.5\%, Astra Zeneca, Istanbul, Turkey) was administered (Figure 3). Then, the patient was placed in the supine position and the head area was raised by 30 degrees. After the patient was covered sterile, the cords of the brachial plexus were seen around the infraclavicular artery from the right side of the patient by costoclavicular approach using USG (Mindray DP-50 
Digital Portable US Machine, Shenzhen, China) Linear Probe. 5\% bupivacaine $(10 \mathrm{ml}=50 \mathrm{mg}$ ) (Marcaine $0.5 \%$, Astra Zeneca, Istanbul, Turkey) that we had already prepared towards 6-9 o'clock of the infraclavicular artery with a $50 \mathrm{~mm}$ block needle (Stimuplex A, B. Braun, Melsungen AG, Ger-many) and 2\% lidocaine (5ml=100mg) (Arithmal 2\% Mg 5mL 5 Ampoules, Adeka, İstanbul, Turkey), a total of $15 \mathrm{ml}$ of local anesthetic was injected, being aspirated at $5 \mathrm{ml}$ intervals. The same procedure was then performed on the left side of the patient (Figure 4). The right and left arms of the patient, who had tissue loss, were covered with dermis equivalent after debridement. The operation took about 2 hours. Analgesia was not needed in this process. No complication was observed in the patient who was followed up postoperatively. The patient did not need any analgesia for 3-4 hours. After the control dressings performed on the $3 \mathrm{rd}$ and 5th days of the hospitalized patient, routine control was recommended and the patient was discharged.

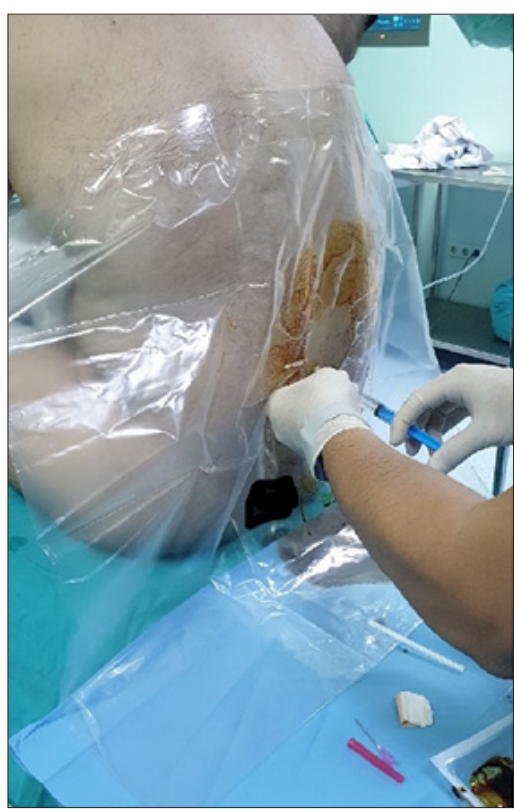

Figure 3: Spinal anesthesia.

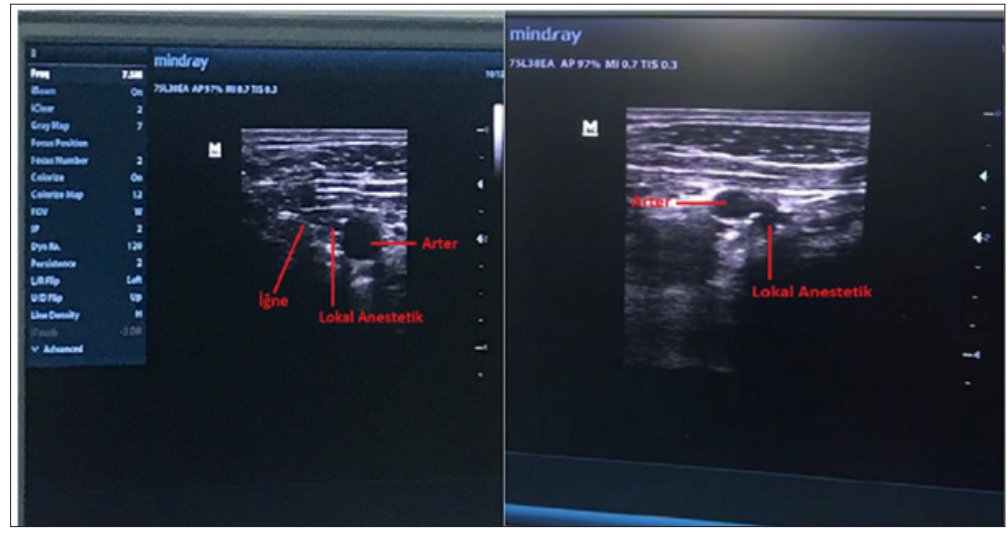

Figure 4: Infraclavicular brachial plexus block ultrasonography image.

\section{Discussion}

Difficult airway is defined as the difficulty experienced by an experienced anesthesiologist in mask ventilation or tracheal intubation or both. Although the incidence varies between $1-13 \%$, severe intubation difficulty can be encountered in $2-3 \%$ of the cases [3]. Difficult intubation and difficult ventilation have many reasons including anatomical, congenital and acquired. Anesthesiologists are often confronted with an operatively difficult airway, especially because of severe acute facial burns or scar tissue on the head and neck after burns. Airway management in these patients during anesthesia complicates anesthesia. Predicting difficult airway and choosing regional anesthesia will decrease the patient's systemic status, postoperative follow-up, mortality and morbidity. In many studies, the choice of regional anesthesia was recommended because of the vasodilatation effect during microvascular surgery and because it accelerated wound healing [4].

Brachial plexus can be blocked by interscalene, supraclavicular, infraclavicular and axillary approaches. Which approach to use may vary depending on the site of operation, the experience of the practitioner, and the anatomy of the patient. Brachial plexus block 
is a very suitable regional anesthesia technique in arm, forearm and hand surgery because it provides good intraoperative anesthesia and long postoperative analgesia. Although brachial plexus block is widely applied unilaterally, bilateral blockade is very rare and usually in case report or very small series $[1,5,6]$.

USG technology is becoming increasingly common in regional anesthesia with the development of portable devices and improved image quality. The use of USG during the block allows the practitioner to see the vascular and neural structures and even the pleura. One of the benefits of USG entering anesthesia practice is to increase the rate of safe and successful block with the use of local anesthetic at lower volume. In particular, fear of toxicity limits bilateral plexus blockade. However, with the guidance of USG, O'Donnell et al. [6] performed successful axillary blockade with $4 \mathrm{ml}$ of local anesthetic [7]. Our experience is that USG-guided lower doses of safe block can be achieved.

Infraclavicular block is used as a publication in arm, forearm and wrist and finger surgery. The success rate in this approach is quite high and the use of USG increases the success rate [8]. Because of the higher risk of phrenic nerve palsy in the interscalene approach, pneumothorax in the supraclavicular approach, and nerve paralysis in the diaphragm, US-guided infraclavicular approach, which is less complicated and commonly used in our clinic, was preferred. Rodriguez et al. [9] showed no adverse effect of infraclavicular blockade with $40 \mathrm{ml} 1.5 \%$ mepivacaine on respiratory function. The low-dose $20 \mathrm{ml}(10 \mathrm{ml} 0.5 \%$ bupivacaine and $10 \mathrm{ml} 2 \%$ prilocaine) that Kayır et al. [10] administered to a high-risk patient was without any complication in a bilateral infraclavicular block patient. Similarly, we did not experience any complications in the bilateral infraclavicular block.

In our case, because of the difficult airway due to orolabial burn accompanying facial burn, regional anesthesia was preferred to increase the blood supply to the extremity and to provide postoperative analgesia. In addition, low burn spinal anesthesia was preferred for the same reasons as burns were present in both lower extremities. USG-guided low-dose bilateral infracalvicular block approach was preferred to reduce pneumothorax, phrenic nerve paralysis, use low-dose local anesthetics, and minimize block failure. Although phrenic nerve paralysis is known to be high in this block, performing this approach with USG guidance minimizes nerve paralysis. We preferred supraclavicular block method because we are successful and experienced in this block in terms of our clinical experience. In our patient, no respiratory distress or any other complications were observed during intraoperative and postoperative periods [11].

In conclusion, it may be a reasonable approach to prefer regional anesthesia especially in cases where surgery is planned for more than one extremity but general anesthesia is considered to be risky. We believe that low-dose bilateral infraclavicular block and low-dose spinal anesthesia can be safely administered under USG guidance because it allows the visualization of the vascular and nerve structures easily and thus decreases the local anesthetic doses significantly, increases the blood supply of the burn wound due to vasodilatation and decreases the need for postoperative analgesics.

\section{References}

1. Tekin M, Gürkan Y, Ceylan DB, Solak M, Toker K (2010) Ultrasoundguided bilateral infraclavicular block: case report. Agri 22(1): 41-43.

2. Sandhu NS, Capan LM (2002) Ultrasound-guided infraclavicular brachial plexus block. Br J Anaesth 89(2): 254-259.

3. Neal JM, Bernards CM, Hadzic A, Hebl JR, Hogan QH, et al. (2008) ASRA Practice advisory on neurologic complications in regional anesthesia and pain medicine. Reg Anesth Pain Med 33(5): 404-415.

4. Çeliker UŞ, Çelebi N (2006) Diffıcult airway and management. Turkiye Klinikleri Journal of Surgical Medical Sciences 2(6): 40-46.

5. Feyhan Ö, Genç (2015) Microsurgery And Anesthesia. Ankara University Faculty of Medicine Journal.

6. O Donnell B, Riordan J, Ahmad I, Iohom G (2010) A clinical evaluation of block characteristics using one milliliter $2 \%$ lidocaine in ultrasoundguided axillary brachial plexus block. Anesth Analg 111(3): 808-810.

7. Hadzic A (2013) Anatomy for regional anesthesia with hadzic peripheral nerve blocks and ultrasound. In: Kurt E (Ed.), Supraclavicular Brachial Plexus Block with Ultrasonography,2 ${ }^{\text {nd }}$ edn, Ankara: Güneș Medical Inscriptions, pp. 361-367.

8. Arcand G, Williams SR, Chouinard P, Boudreault D, Harris P, et al. (2005) Ultrasound-guided infraclavicular versus supraclavicular block. Anesthesia and Analgesia 101(3): 886-890.

9. Soares LG, Brull R, Lai J, Chan VW (2007) Eight ball, corner pocket: The optimal needle position for ultrasound-guided supraclavicular block. Reg Anesth Pain Med 32(1): 94-95.

10. Bhatia A, Lai J, Chan VWS, Brull R (2010) Pneumothorax as a complication of the ultrasound-guided supraclavicular approach for brachial plexus block. Anesthesia and Analgesia 111(3): 817-819.

11. Yang CW, Kwon HU, Cho CK, Jung SM, Kang PS, et al. (2010) A comparison of infraclavicular and supraclavicular approaches to the brachial plexus using neurostimulation. Korean J Anesthesiol 58(3): 260-266.

For possible submissions Click below: 